Revista Universo Contábil, ISSN 1809-3337

FURB, v. 6, n.2, p. 61-81, abr./jun., 2010

doi:10.4270/ruc.2010213

Disponível em www.furb.br/universocontabil

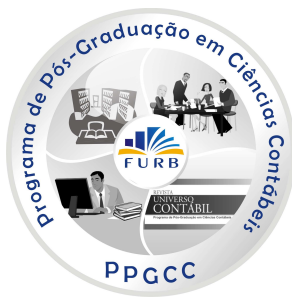

\title{
SEGURO AMBIENTAL COMO MECANISMO DE MINIMIZAÇÃO DO PASSIVO AMBIENTAL DAS EMPRESAS*
}

\section{ENVIRONMENTAL INSURANCE AS A MINIMIZATION MECHANISM OF COMPANIES' ENVIRONMENTAL LIABILITY}

\author{
Aucilene Vasconcelos Hahn \\ Mestre em Contabilidade pela FUCAPE Business School \\ Endereço: Av. Fernando Ferrari, 1358, Goiabeiras \\ CEP: 29075-010 - Vitória ES - Brasil \\ E-mail: aucilenevas@yahoo.com.br \\ Telefone: (27) 4009-4444 \\ Idália Antunes Cangussú Rezende \\ Mestre em Contabilidade pela FUCAPE Business School \\ Endereço: Av. Fernando Ferrari, 1358, Goiabeiras \\ CEP: 29075-010 - Vitória ES - Brasil \\ E-mail: idaliaantunes@yahoo.com.br \\ Telefone: (27) 4009-4444 \\ Valcemiro Nossa \\ Doutor em Controladoria e Contabilidade pela FEA/USP \\ Professor de Contabilidade da FUCAPE Business School \\ Endereço: Av. Fernando Ferrari, 1358, Goiabeiras \\ CEP: 29075-010 - Vitória ES - Brasil \\ E-mail: valcemiro@fucape.br \\ Telefone: (27) 4009-4444
}

\section{RESUMO}

Objetivou-se neste estudo investigar sobre o funcionamento do seguro de riscos ambientais como mecanismo de redução ou eliminação de passivos ambientais, bem como a sua aplicabilidade mercadológica no Brasil. O mercado securitário nacional oferece uma gama de coberturas referentes aos riscos de poluição ambiental. As apólices possuem diferentes

\footnotetext{
Artigo recebido em 30.09.2008. Revisado por pares em 11.02.2009. Reformulado em 15.09.2009. Recomendado para publicação em 24.09.2009 por Ilse Maria Beuren (Editora). Publicado em 30.06.2010. Organização responsável pelo periódico: FURB.
} 
coberturas, tanto para atender à demanda quanto à poluição súbita, que gera segundo Durço (2001) desastres ambientais de larga repercussão e poluição gradual que persiste por um longo período de tempo. O método de pesquisa utilizado foi o empírico-analítico que privilegia abordagem de estudos práticos com a coleta de dados. Para esta pesquisa foram enviados questionários para 71 empresas de seguros que atuam no Brasil e que são filiadas à Federação Nacional das Empresas de Seguros Privados e de Capitalização (FENASEG). Os resultados encontrados indicam que o nível de oferta do seguro de riscos ambientais no Brasil, como mecanismo de ajuda na minimização de passivos ambientais, ainda é pequeno devido às diversas dificuldades que o mercado segurador enfrenta para operar com este tipo de seguro. Dessa forma, conclui-se, que existe a necessidade de se ampliar o conhecimento do mercado segurador brasileiro, em relação à subscrição de riscos ambientais e coberturas mais complexas, que apresentem soluções adequadas aos empresários e que passem a questionar a sua exposição a esse tipo de risco.

Palavras-chave: Seguro ambiental. Passivo ambiental. Gestão ambiental. Contabilidade ambiental.

\section{ABSTRACT}

The goal of this study is to investigate the functioning of the environmental risk insurance as a mechanism to reduce or eliminate environmental liabilities, as well as its application in the Brazilian market. The national insurance market offers a wide range of coverage for risks of environmental pollution. The policies have different coverage, both against recurring risks and risks of sudden pollution events, which according to Durço (2001, p. 4) generate environmental disasters with wide repercussion, which persist for a long period. The research method used was the empirical-analytical approach which emphasizes practical study with data collection. In order to conduct this research, questionnaires were sent to 71 Brazilian insurance companies, members of the National Insurance Industry Association (FENASEG). The results indicate that the level of insurance against environmental risks offered in Brazil, as a mechanism to help minimizing environmental liability, is still being small due to several difficulties faced by the insurance market to operate with this type of coverage. Thus, we conclude that there is a need for increased knowledge in the Brazilian insurance market regarding underwriting environmental risks and more complex coverage, to satisfy the needs of companies to reduce their exposure to this type of risk.

Keywords: Enviornmental insurance. Environmental liability. Environmental management. Environmental accounting.

\section{INTRODUÇÃO}

A prática de se procurar mecanismos para assegurar o patrimônio é bastante antiga, fazendo parte da história da humanidade, passando por grande evolução, provocando mudanças de acordo com as características dos momentos históricos vividos, adaptando-se essa prática às necessidades que foram surgindo ao longo do tempo.

$\mathrm{O}$ crescimento industrial aconteceu em todas as áreas: siderurgia, têxtil, alimentos etc. Entretanto, este crescimento sempre visou o lucro das empresas e não houve preocupação com a preservação do meio ambiente. Como conseqüência, os recursos naturais começaram a se esgotar devido ao seu uso desordenado. Muitos equipamentos eram e ainda são altamente poluidores, causando contaminações dos rios, mares, ar, fauna, flora, além de comprometer a qualidade de vida das pessoas, gerando vários problemas de saúde. As empresas não se 
preocupavam com os impactos ambientais que geravam. Em decorrência disso, pode-se acompanhar, em várias partes do planeta, vários acidentes ambientais.

A humanidade passou a conviver com impactos e acidentes ambientais de diversas ordens. Esses acontecimentos fizeram surgir, de forma lenta e gradual, uma consciência ecológica na sociedade, governos, estados, órgãos específicos de fiscalização e ambientalistas.

No Brasil, os riscos ambientais têm crescido, em decorrência de graves desastres ecológicos, podendo-se citar, por exemplo, os casos envolvendo a “... Petrobrás S.A, com os derramamentos de milhões de toneladas de óleo cru na Baía da Guanabara, nos rios Paraná, na Bacia de Campos e outros" (DURÇO, 2001, p. 01). Um acidente ocorreu, em janeiro de 2000, na Baía de Guanabara, com o rompimento de um oleoduto e o vazamento de 1,3 milhões de litros de óleo, e outro, em fevereiro de 2001, em Morretes, no Paraná, decorrente do vazamento de 50.000 litros de óleo diesel.

No cenário mundial, segundo Ribeiro e Lisboa (2000, p. 09) destacam-se os acidentes "provocados pelo petroleiro Exxon-Valdez, no Alasca, pelos resíduos de materiais nucleares em Chernobyl, na Rússia", este ocorrido em 1986, entre outros.

$\mathrm{Na}$ análise de risco ambiental, de acordo com MacDowell e Corrêa (1997, p. 01), “o setor de seguros parece ser o mais ativo participante da análise de risco ambiental de grandes projetos", pois as questões envolvendo o meio ambiente são globais e, cada vez mais, o mercado de seguros brasileiro se desenvolverá neste campo.

As sociedades seguradoras desenvolveram estratégias de gestão de risco, evitando assim, potenciais perdas. Os seguros são a principal ferramenta de controle de risco das empresas seguradas, uma vez que transferem o custo das perdas para a entidade seguradora.

A responsabilidade civil da empresa tem gerado medidas de prevenção para eliminar impactos ambientais, devido ao entendimento de que a legislação ambiental brasileira, que em seu art. 14, parágrafo $1^{\circ}$, da Lei ${ }^{\circ}$ 6.938/81 (Política Nacional do Meio Ambiente), descreve:

$\S 1^{\circ}$ - Sem obstar a aplicação das penalidades previstas neste artigo, é o poluidor obrigado, independentemente de existência de culpa, a indenizar ou reparar os danos causados ao meio ambiente e a terceiros, efetuados por sua atividade. O Ministério Público da União e dos Estados terá legitimidade para propor ação de responsabilidade civil e criminal por danos causados ao meio ambiente (BRASIL, 1981, p. 02).

Green (2002) desta que se uma empresa possui problemas ambientais ocorridos no passado e que gerando um risco futuro com a necessidade de se constituir uma provisão para contingência ambiental, segundo as normas contábeis, uma forma de minimizar esse possível passivo ambiental seria a contratação de um seguro de riscos ambientais.

O mercado securitário nacional oferece uma gama de coberturas referentes aos riscos de poluição ambiental. As apólices possuem diferentes coberturas, tanto para atender à demanda, quanto à poluição súbita, que gera, segundo Durço (2001, p. 04), "os chamados desastres ambientais de larga repercussão" e a poluição gradual, que persiste por um longo período de tempo. Diante do exposto, esta pesquisa se propõe a investigar as seguintes questões de pesquisa: Quais as características do seguro de riscos ambientais e qual o nível de oferta do seguro de riscos ambientais no Brasil como mecanismo de ajuda na diminuição de passivos ambientais?

O objetivo deste estudo é investigar como é o funcionamento do seguro de riscos ambientais como mecanismo de redução ou eliminação de passivos ambientais, bem como a sua aplicabilidade mercadológica no Brasil. Uma justificativa para o estudo desse tema é apresentada por Mendonça e Souza (2002, p. 22): 
disponibilidade imediata de valores para recomposição de danos, colocando em prática um dos principais conceitos da nova ordem econômica: a imediata satisfação da comunidade.

Considerando que é perceptível o crescimento do nível de pressão que a sociedade organizada vem desenvolvendo sobre os negócios no que se referem à preservação do meio ambiente, cada vez mais as empresas são forçadas a reconhecer os possíveis riscos ambientais em seus balanços. Assim, o estudo do tema seguro ambiental é uma oportunidade para despertar nas empresas mais esse mecanismo de redução do risco econômico-financeiro futuro nas empresas, principalmente por ser ainda pouco explorado no meio acadêmico.

\section{METODOLOGIA}

Para a realização da pesquisa, investigou-se o Seguro de Riscos Ambientais como mecanismo de minimização do Passivo Ambiental das empresas, adotando-se a pesquisa de campo. O método da pesquisa utilizado foi o empírico-analítico, que privilegia a abordagem de estudos práticos e, de acordo com Martins (1994, p. 26), suas propostas têm caráter técnico, restaurador e incrementalista.

Para esta pesquisa, foram enviados questionários para 71 empresas de seguros que atuam no Brasil e que são filiadas a Federação Nacional das Empresas de Seguros Privados e de Capitalização (FENASEG). O questionário consta de onze questões fechadas. Estas são divididas em sete questões dicotômicas que, segundo Martins (2000, p. 50), consistem em "uma pergunta com duas respostas possíveis" e quatro questões de múltipla escolha que, para Martins (2000, p. 50), é "uma pergunta com várias alternativas de respostas".

O questionário foi escolhido, dentre as técnicas utilizadas para coleta de dados, por ser um trabalho empírico, inclui dados sobre a operação de Seguro de Risco Ambiental e o nível de oferta no Brasil, e sobre o interesse do mercado securitário em acompanhar o passivo ambiental das empresas seguradas. Em todas as questões do questionário existem perguntas opcionais, em que as seguradoras poderiam expor sua opinião relacionada a cada pergunta.

Os questionários foram enviados via e-mail, contendo em anexo, uma carta de apresentação relatando a importância e o objetivo da pesquisa envolvendo o estudo da aplicabilidade do Seguro de Riscos Ambientais como minimização do Passivo Ambiental das empresas. Para encaminhar os questionários foi usada a lista das empresas de seguros que constam no site da FENASEG.

Dos 71 questionários enviados, dois foram respondidos por resseguradoras e onze foram respondidos por seguradoras, o que representa $18,31 \%$ do total enviado. Resseguardora é a pessoa jurídica que aceita, em resseguro, a totalidade ou parte das responsabilidades repassadas pela seguradora direta, ou por outros resseguradores, recebendo esta última operação o nome de retrocessão (GLOSSÁRIO FUNENSEG, 2002).

Nove e-mails foram devolvidos sem o questionário respondido, com várias justificativas. Entre os comentários, pode-se destacar uma seguradora que pertence a uma instituição financeira que alegou questões de sigilo bancário, não autorizando responder pesquisas. Outras oito seguradoras responderam que não trabalham com este tipo de seguro, não respondendo o questionário. Algumas companhias de seguros indicaram o especialista em Seguros Ambientais, Sr. Walter Antonio Polido (2005), da resseguradora Munich Re, que auxiliou neste trabalho enviando, por e-mail, artigos de sua autoria e o questionário respondido com algumas observações relacionadas a cada questão do questionário.

O restante, ou seja, 49 questionários, não foram devolvidos pelas seguradoras, mesmo após as insistentes cobranças por e-mail e telefone. Com base nos 13 questionários respondidos foi feita a análise que deu origem aos resultados desta pesquisa. Os respondentes 
alvos da investigação foram os presidentes das seguradoras, diretores técnicos, analista de marketing e gerente de produção.

\section{SEGURO AMBIENTAL}

\subsection{Retrospectiva Histórica da Prática do Seguro nas Organizações}

O instinto de preservação de seu patrimônio está presente na vida humana, desde quando o homem ainda não se preocupava com acumulação de bens, a não ser para garantir a sua sobrevivência. Assim, visando resguardar-se dos riscos que enfrentava constantemente, os indivíduos buscaram a "formação de grupos e a fixação em regiões que lhes proporcionassem segurança e condições de sobrevivência" (SOUZA, 2001, p. 19).

Esse fenômeno da convivência em grupo deu origem ao mutualismo, que foi adotado de formas diferentes pelas sociedades. Mutualismo é a formação de um grupo de pessoas com interesses em comum constituindo uma reserva econômica para dividir o risco de um acontecimento não previsto. Souza (2001, p. 04) apresenta alguns exemplos desse fenômeno:

[...] os comerciantes da Babilônia no século XIII, preocupados com o risco de perda dos camelos na travessia do deserto em direção aos mercados das regiões vizinhas, formavam acordos nos quais: quem perdesse um camelo, na travessia pelo deserto, por desaparecimento ou morte, receberia outro, pago pelos demais criadores. Também na Babilônia, por volta de 1800 A.C. surgia o Código de Hamurabi, prevendo que os navegadores deveriam se associar para ressarcir aquele que perdesse o seu navio em alguma tempestade.

Com o surgimento de uma nova modalidade de seguros chamada Contrato de Dinheiro e Risco Marítimo, no século XII da era cristã, que era realizado através de um contrato bilateral, ou seja, um documento assinado por duas pessoas,

sendo uma delas a que emprestava ao navegador quantia em dinheiro no valor do barco e das mercadorias transportadas. Se durante a viagem o barco sofresse alguma avaria, o dinheiro emprestado não era devolvido. Caso contrário esse dinheiro voltava para o financiador acrescido de juros (HISTÓRIA..., 2002, p. 01).

A prática do mutualismo foi proibida pela igreja católica, na Idade Média, pois foi classificada como prática abusiva, baseando-se em um dos sete pecados capitais, a usura. $\mathrm{O}$ Papa Gregório IX, em 1234, determinou que "somente a vontade divina seria capaz de minorar as desgraças e infortúnios do homem" (SOUZA, 2001, p. 5).

Com a proibição, pelo Papa Gregório IX do seguro marítimo, o papel dos financiadores passou para os banqueiros que se tornavam compradores das navegações e das mercadorias; "se o barco chegasse intacto ao seu destino, a cláusula de compra se tornava nula e o dinheiro era devolvido ao banqueiro, acrescido de outra quantia como rendimento do empréstimo feito" (HISTÓRIA..., 2002, p. 01). Essas sociedades de banqueiros são as que originaram às atuais sociedades seguradoras.

O segundo marco foi a fundação da Lloyds, em 1678, em Londres por Edward Lloyds. Tudo iniciou quando Lloyds fundou um café, por volta de 1660, que era o ponto de encontro de navegadores e pessoas interessadas nos negócios de seguros, como banqueiros e financistas. Na parede da cafeteria ficavam escritos os nomes dos navios e os acontecimentos das viagens. Os navegadores que gostariam de dividir os riscos da viagem "escrevia seu nome e o montante de risco que gostaria de ver assegurado embaixo, sendo, assim, conhecidos como underwriters" (SOUZA, 2001, p. 46). Originou-se assim o termo underwriters que são exatamente as pessoas encarregadas de subscrever riscos. 
No Brasil, a atividade seguradora iniciou-se em 1808 com a abertura dos portos brasileiros ao comércio internacional por D. João VI, por meio "da primeira seguradora no país, a Companhia de Seguros Boa Fé, na capitania da Bahia” (BRASIL..., 2002, p. 01). Um destaque na história do seguro no Brasil, segundo o Anuário Estatístico da SUSEP, foi a criação em 1939 do "Instituto de Resseguros do Brasil (IRB), através do Decreto-lei n. ${ }^{\circ}$ 1.186, de 3 de abril de 1939" (HISTÓRIA..., 2002b, p. 7).

As companhias seguradoras, desde então, estavam obrigadas a ressegurar no IRB as responsabilidades que excedessem sua capacidade de retenção própria, que, por intermédio do retrocesso, passou a compartilhar o risco com as companhias seguradoras no Brasil. Assim, o governo procurou evitar que as divisas fossem consumidas com as remessas para o exterior de valores altos relativos a prêmios de resseguros em companhias estrangeiras.

Com o término do monopólio do resseguro pelo IRB, de acordo Mendonça e Souza (2002, p.12) "cerca de 20 resseguradoras de renome internacional instalaram seus escritórios nas principais cidades do Brasil". A abertura do mercado ao capital estrangeiro (FIGURA 1), gerada pela globalização, inovou o mercado segurador brasileiro. Porém, os seguros tradicionais são de automóveis, vida e saúde (SOUZA, 2001, p. 12).

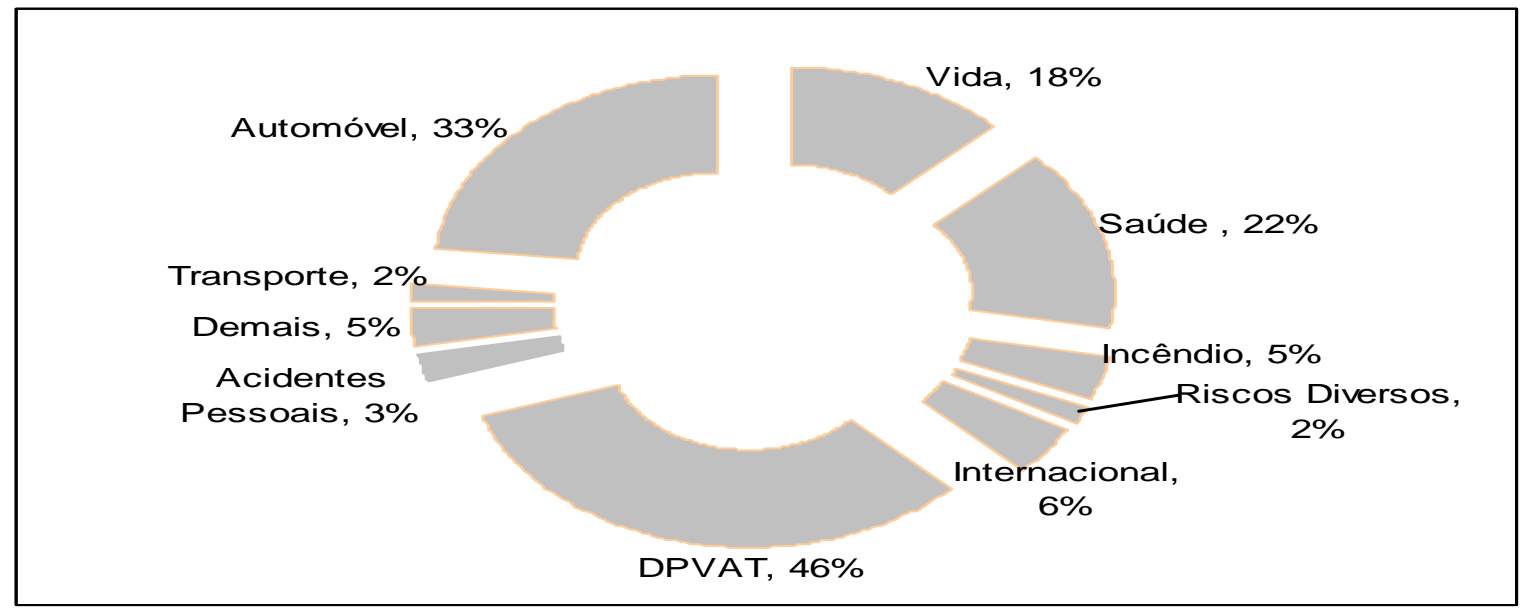

Figura 1- Participação dos diferentes tipos de seguro no Brasil Fonte: Souza (2001).

É nesse contexto, que o seguro de riscos ambientais desponta como algo novo e desconhecido para muitos, pois é, segundo Hurtado (1997, p. 16), "completamente diferente do vasto conjunto de produtos disponíveis que estes corretores estão acostumados a oferecer a seus compradores".

\subsection{Seguro de Riscos Ambientais no Brasil}

A preocupação com o seguro ambiental surgiu no Brasil na década de 70, quando o mercado começou a buscar alternativas para "resolver a questão da subscrição dos riscos envolvendo danos ambientais" (POLIDO, 2002, p. 1).

Em 1978, "a FENASEG (Federação Nacional das Empresas de Seguros e de Capitalização) constituiu um Grupo de Trabalho, o qual desenvolveu um projeto de Seguros de Riscos de Poluição do Meio Ambiente" (POLIDO, 1995, p. 83).

No decorrer dos anos ocorreram grandes transformações na legislação, como a introdução da Lei n. ${ }^{\circ}$ 6.938/81 (Lei da Política Nacional do Meio Ambiente), Lei n. ${ }^{\circ}$ 7.347/85 (Ação Civil pública por Danos causados ao Meio Ambiente) e a Constituição Federal de 1988, que consagra o Capítulo VI, especialmente à proteção do Meio ambiente, de acordo o art. 225 da Constituição da República Federativa do Brasil, de 5 de outubro de 1988: 
Todos têm direito ao meio ambiente ecologicamente equilibrado, bem de uso comum do povo e essencial à sadia qualidade de vida, impondo-se ao Poder Público e à coletividade, o dever de defendê-lo e preservá-lo para as presentes e futuras gerações.

Uma vez que o Brasil já possuía uma legislação abrangente na área de proteção do meio ambiente, formou-se um novo Grupo de Trabalho (GT), por meio da iniciativa do Instituto de Resseguros do Brasil (IRB), com a finalidade de buscar soluções dentro do âmbito do seguro ambiental. Dez anos após a realização da histórica Rio 92, o Programa das Nações Unidas para o Meio Ambiente (Pnuma) afirmou, segundo Leal (2002, p. 01), que "os danos ambientais não são um prognóstico ou um pesadelo; são um fato [...], durante a Rio 92, os países firmaram uma série de compromissos de preservação, mas não pensaram em garantir sua aplicação".

O meio ambiente continua a ser desvalorizado e cada vez mais degradado, apesar de alguns avanços. De acordo com Durço (2001, p. 02), o seguro ambiental é caracterizado pelo "atendimento das obrigações reparatórias e indenizatórias de parte do agente poluidor, e ao mesmo tempo possibilitaria, com as devidas correções, a continuidade da atividade empresarial". Segundo Mello (1999, p. 23), "a possibilidade de que o risco ambiental se transforme em um risco segurado está intimamente ligada com a existência de normas claras e precisas para a prevenção deste tipo de dano”. Somente quando o poder judiciário brasileiro responsabilizar, com maior rigor, as empresas que causam danos ao meio ambiente, o seguro ambiental ocupará seu lugar no mercado segurador brasileiro.

A internacionalização no setor de seguros refletiu na abertura do mercado de seguros brasileiro, gerando grandes fusões e aquisições, com investimentos externos, e a desmonopolização do resseguro ocorrida em 1996. Outro fato marcante foi a evolução da legislação de proteção ao meio ambiente, com a Lei $\mathrm{n}^{\circ}$ 9.605, de 12 de fevereiro de 1998 (Lei de Crimes Ambientais). Essa Lei prevê entre outras coisas, a responsabilidade penal da pessoa jurídica como sujeito ativo do crime ecológico, como é relatado no art. $3^{\circ}$ :

As pessoas jurídicas serão responsabilizadas administrativa, civil e penalmente conforme o disposto nesta Lei, nos casos em que a infração seja cometida por decisão de seu representante legal ou contratual, ou de seu órgão colegiado, no interesse ou benefício da sua entidade [grifo nosso].

A ocorrência de sinistros com grandes proporções, relacionadas com derramamento de petróleo, como os ocorridos na Baía de Guanabara, nos rios do Paraná, na Bacia de Campos e outros, levaram os seguradores nacionais a se conscientizarem do problema que gera esses graves desastres ecológicos.

\subsection{Conceituação do Seguro de Riscos Ambientais}

A Federação Nacional das Empresas de Seguros Privados e de Capitalização (FENASEG), fundada em 1951, entidade que congrega as empresas do setor de seguros, explicita que:

\footnotetext{
Denomina-se contrato de seguro aquele que estabelece para uma das partes, mediante recebimento de um prêmio da outra parte, a obrigação de pagar a esta, ou à pessoa por ela designada, determinada importância, no caso da ocorrência de um evento futuro e incerto ou de data incerta, previsto no contrato (GLOSSÁRIO FENASEG, 2002, p. 11).
} 
Os riscos ambientais podem ser definidos, segundo Hurtado (1997, p. 07), como "riscos que podem provocar conseqüências ao meio ambiente, constituindo-se em uma ameaça às alterações ou influências químicas ou físicas danosas aos organismos vivos". O contrato de seguro ambiental é bilateral, pois cria obrigações de ambas as partes, tanto para o segurado quanto para o segurador. E oneroso porque gera dispêndio para o segurado e o segurador.

De acordo com Durço (2001, p. 03), o seguro de riscos ambientais possui uma "natureza jurídica e os elementos próprios do contrato de seguro, assim seriam bilateral, oneroso, aleatório, consensual e inclusive solene, guardando peculiaridades específicas". Além de ser da mais estrita boa-fé, ou seja, “... o conhecimento do risco pela seguradora depende da fidedignidade das informações prestadas pelo segurado, de modo a não induzir a outra parte a engano ou erro" (MENDONÇA; SOUZA, 2002, p. 31).

A natureza dos riscos é determinante para classificar os seguros em três grandes tipos, que são o "seguro de pessoas, danos patrimoniais e prestação de serviços" (SOUZA, 2001, p. 62). Riscos são eventos incertos ou de data incerta que independe da vontade das partes contratantes e contra o qual é feito o seguro. Os riscos são a expectativa de sinistro. Sem risco não pode haver contrato de seguro (DICIONÁRIO FUNENSEG, 2002, p. 18).

Nos seguros de prestação de serviços, o segurado deseja a proteção e o ressarcimento dos gastos referentes à prestação de serviços. Os seguros de prestação de serviços tradicionais abrangem o seguro de responsabilidade civil e o seguro de lucros cessantes. De acordo com Souza (2001, p. 73), o seguro de responsabilidade civil,

\begin{abstract}
garante o reembolso de indenizações que o segurado venha a ser obrigado a pagar em consequiência de lesões corporais ou danos materiais, sofridas por terceiros por culpa involuntária do segurado ou de pessoas pelas quais deva responder civilmente. O Mercado Segurador Brasileiro oferece várias coberturas de responsabilidade civil, pertinentes aos riscos da poluição, onde o risco é alocado em vários ramos de seguros, de acordo com o tipo de atividade do segurado.
\end{abstract}

\title{
3.4 O Seguro de Responsabilidade Civil - Poluição Ambiental
}

O Seguro de Responsabilidade Civil - Poluição Ambiental, instituído no Brasil em 26 de dezembro de 1991, por meio da circular PRESI - 052, do IRB - Brasil Resseguros, "cujo modelo de cobertura, com caráter facultativo quanto à sua operacionalização, foi definitivamente apresentado ao Mercado Nacional” (POLIDO, 1995, p. 110).

A apólice de Seguro Responsabilidade Civil - Poluição Ambiental oferece a cobertura ampla, para atender a demanda quanto à poluição súbita e gradual e mais às coberturas que abrangem. Apólice é o contrato de seguro que estabelece os direitos e obrigações da companhia de seguros e do segurado (GLOSSÁRIO FENASEG, 2002, p. 01). Segundo Polido (1995, p. 118):

a) Danos Pessoais e Materiais causados a Terceiros, quando no Território Brasileiro, inclusive as perdas financeiras relacionadas com o uso de tais propriedades;

b) Custas Judiciais e Honorários Advocatícios - Foro Cível;

c) Despesas para neutralizar ou limitar as conseqüências de um sinistro;

d) Despesas com defesa do Segurado na Esfera Criminal.

A poluição consiste na contaminação dos ambientes vitais, que são terra, água e ar, pela introdução de substâncias nocivas, acarretando efeitos negativos sobre os minerais, vidas animal e vegetal. Para Gomes e Pereira (2002, p. 03), "do ponto de vista da seguradora, ela está encarada como um evento gradual ou como um evento súbito". 
Devido a esta definição, a apólice garante a cobertura, tanto para poluição súbita, quanto para poluição gradual. Entretanto, o seguro é, na maioria das situações, realizado com base na poluição súbita (Responsabilidade Civil Geral), pois a auditoria ambiental, realizada pelas seguradoras, bancos ou instituições independentes, consegue mensurar mais facilmente os riscos súbitos através de perícias, segundo Minc (2002, p. 16),

as auditorias bem feitas e com as medidas tomadas não só previnem e diminuem os riscos como dão uma base para alguém que vá a uma seguradora fazer um seguro ambiental. De posse das informações geradas pela auditoria ambiental a empresa tem noção das margens de risco e do tamanho possível do dano.

A cobertura ampla envolve o risco de poluição gradual que, segundo Polido (1995, p. 111), é:

aquela poluição/contaminação de forma paulatina, resultado de um processo lento e às vezes imperceptível. É o caso típico de vazamentos de tanques subterrâneos que, acontecendo durante algum tempo, fatalmente serão descobertos posteriormente, quando a substância vazada atingir, por exemplo, poços e/ou depósitos de águas adjacentes, provocando danos a terceiras pessoas.

Os danos causados por acumulações graduais ou paulatinas, ou seja, as coberturas que envolvem o risco de poluição gradual são de difícil subscrição pelos mercados de seguros e de resseguros. O seguro de poluição gradual não é uma prática habitual, pois, de acordo MacDowell e Corrêa (1997, p. 02), "dificilmente se consegue analisar todas as características ambientais que podem estar ou virem a ser envolvidas".

A apólice também garante a responsabilidade civil do segurado em relação às reparações por danos ambientais e conseqüentes danos corporais ou materiais, involuntariamente e acidentalmente, causados a terceiros, em decorrência de poluição ambiental e "provocada pelas operações dos estabelecimentos industriais previstos no contrato" (POLIDO, 2002, p. 05). De acordo com as condições gerais para o Seguro de Responsabilidade Civil Poluição Ambiental da Circular PRESI - 023, de $1^{\circ}$ de agosto de 1997 (IRB, 1997):

O presente seguro tem por objetivo reembolsar o Segurado das quantias pelas quais vier a ser responsável civilmente, relativas a reparações por danos pessoais ou materiais, involuntariamente causados a terceiros em decorrência de poluição ambiental provocada pelas operações do(s) estabelecimento(s) especificado(s) na apólice.

Além das coberturas citadas, existem as mencionadas em parágrafo anterior que são as despesas de contenção, que servem para neutralizar ou limitar as consequiências de um acidente, evitando o sinistro, bem como as custas judiciais e honorários advocatícios para a defesa do segurado na esfera cível e as despesas com a defesa do segurado na esfera criminal, que fica a critério da seguradora. É fundamental salientar que a responsabilidade da seguradora é limitada ao capital indicado na apólice, ou seja, a importância segurada, que deve ser determinada pelo próprio segurador, quando ocorrer a contratação do Seguro Responsabilidade Civil - Poluição Ambiental.

Para contratação do referido seguro, a empresa segurada preenche um questionário padrão, cujo modelo encontra-se na Circular PRESI - 023/97 (IRB, 1997), que complementa a proposta de seguro, para uma análise preliminar do risco pela seguradora, "visando não só fornecer os dados necessários à analise e à cotação do prêmio do seguro, mas também oferecer os elementos básicos à inspeção técnica do risco" (POLIDO, 1995, p. 133).

Um roteiro de inspeção, que está consagrado no Anexo 2 da Circular PRESI -023/97 (IRB, 1997), acontece nos locais que deverão ser abrangidos pelo seguro, é realizado como 
uma espécie de auditoria ambiental, que, segundo Minc (2002, p. 16), "é uma boa base para a contratação de um seguro ambiental e é bom também para a empresa segurada e para a seguradora". Para Polido (2002, p. 06), existem diversos benefícios gerados por uma auditoria, tais como:

a) Aumento da credibilidade externa em relação à empresa;

b) Estabelece critérios de emergência, no caso de acidentes;

c) Minimiza a produção de resíduos;

d) Assegura aos diretores, acionistas e investidores, que medidas estão sendo tomadas para controlar a possibilidade de ocorrer acidentes indesejáveis;

e) Detecta e corrige maus procedimentos em relação à estocagem de produtos perigosos e outros;

f) Proporciona, enfim, segurança à empresa.

A tarifação, que consiste na avaliação do risco ambiental, é a etapa final, e devido ao fato do seguro de riscos ambientais ter uma tendência de sinistros catastróficos, possui custo elevado e são usados vários fatores na análise do risco e na composição do custo dos prêmios que são divididos em duas etapas. A primeira considera os fatores de emissão de poluentes e os fatores de riscos representados pela própria empresa segurada. Essa etapa denomina-se Localização do Risco Segurável que, segundo Polido (2002, p. 06), envolve:

a) Tipo de Atividade desenvolvida pelo Segurado;

b) Tipo de Processos aplicados na indústria;

c) Tipo de Emissões - Atmosfera - Água - Solo;

d) Tipo de Tratamento aplicado para os resíduos;

e) Quantidade de Poluentes estocada;

f) Tipo de utilização dos recursos naturais; e

g) Proteções e Planos Emergenciais disponíveis.

A segunda etapa considera o potencial de sinistros presentes na circunvizinhança da empresa, com determinação de uma possível ocorrência, denominando-se Extensões Prováveis, que são, de acordo com Polido (2002, p.06):
a) Tipo da vizinhança - densidade da população existente;
b) Valores acumulados na circunvizinhança - naturais e edificados;
c) Serviços públicos existentes; e
d) Transporte das emissões - condições geológicas, hidrológicas e atmosféricas.

Em relação ao Seguro de Responsabilidade Civil - Poluição Ambiental que consiste na cobertura ampla, o mercado securitário brasileiro enfrenta dificuldades, devido a diversos fatores. Entre eles, destacam-se as dificuldades de se identificarem os riscos, as empresas seguradas vêem o seguro como despesa e não como investimento de longo prazo. Algumas seguradoras alegam que não existem compradores para este tipo de seguro e é considerado por muitos “... uma área meio nebulosa, pois não existem profissionais nas seguradoras que entendam do assunto" (POLUIÇÃO..., 2001, p. 04). De acordo com Polido (2002a), praticamente ninguém contrata ou contratou no Brasil, o seguro específico de Responsabilidade Civil - Poluição Ambiental da Circular PRESI - 023/97 (IRB, 1997).

\subsection{Formação de Pools - Um Desafio ao Mercado Segurador Brasileiro}

As coberturas para poluição ambiental, em praticamente todos os países, são limitadas às "situações poluentes ou contaminantes causadas por um evento súbito e inesperado [...], por exemplo, no caso da Sandoz que ocorreu em 1986, em que um incêndio implicou na 
contaminação do Reno com uma mistura de produto químicos à água utilizada no combate a esse incêndio" (GOMES; PEREIRA, 2002, p. 11).

As coberturas para os danos causados por acumulação gradual são excluídas das apólices, podendo ser encontradas em "alguns poucos países, tais como na Alemanha, França, Suíça, Bélgica, Suécia, EUA, Itália e, também no Brasil” (POLIDO, 1995, p. 11).

A formação de Pools é uma solução encontrada por alguns desses países para a subscrição de riscos de natureza gradual, ou seja, "a que ocorre de forma lenta e paulatina, mas sempre involuntária" (SÁNCHEZ, 2001, p. 191). O Pool de Resseguro consiste em um consórcio, em que as seguradoras aderentes resseguram uma às outras, "executando o trabalho operacional que inclui o underwriting e a liquidação de sinistros por meio de Comitês e, freqüentemente, oferecem uma cobertura bem mais ampla daquela disponível no mercado padrão" (POLIDO, 1995, p. 104).

Devido às dificuldades de implantação do seguro de riscos ambientais, países como França, Itália, Holanda e Espanha formaram vários Pools de Resseguro, onde seguradoras e resseguradoras compõem um sistema de consórcios que, segundo Gomes e Pereira (2002, p. 11), é uma primeira "constatação das seguradoras, de que pode ser bastante difícil manteremse sós num mercado com muito poucas apólices, mas bastante complexo e com vultosas indenizações".

A individualização das seguradoras na subscrição apresenta desvantagens "neste segmento de risco onde o fator concorrência parece ficar em segundo plano, face não só a alta exposição do mesmo, como também pelo fato de requerer investimentos na área de underwriting", segundo Polido (2002a, p. 03).

Os países citados encontraram nos Pools de Resseguro, um caminho para a subscrição de riscos ambientais, "já que o risco de danos causados ao ambiente pode atingir dimensões de natureza catastrófica" (GOMES e PEREIRA, 2002, p. 11).

A formação de pools brasileiros, para subscrição de riscos ambientais, pode ser uma solução para o mercado do seguro ambiental no Brasil, pois, segundo Polido (2002a, p. 11), "o Mercado Segurador Brasileiro deverá procurar as suas soluções, já que fórmulas simplistas não serão eficazes a médio e longo prazo".

Embora o seguro de riscos ambientais no Brasil apresente grande dificuldade para uma comercialização que abranja todas as coberturas especificadas na apólice, as perspectivas de mercado são cada vez mais globais e as preocupações com o Desenvolvimento Sustentável, ocasionarão, cedo ou tarde, um posicionamento do setor securitário brasileiro em relação aos seguros do meio ambiente. Em relação ao Desenvolvimento Sustentável, Hurtado (1997, p. 03) descreve como sendo o "desenvolvimento que satisfaça as necessidades do presente sem comprometer a capacidade das futuras gerações em satisfazer as suas próprias". Diante de tal situação, o Brasil, segundo Polido (2002, p. 08),

Certamente encontrará o seu caminho no momento certo e de acordo com a conjunção de uma série de fatores evidentemente. Não há como prever ou mesmo de precipitarmos este momento. Cada país e respectivo mercado de seguros teve o seu ou ainda terá também, tal como o Brasil.

\section{SISTEMA DE GESTÃO AMBIENTAL}

O crescimento industrial ajudou o desenvolvimento sócio-econômico dos países industrializados, mas, por outro lado, prejudicou e ainda prejudica o meio ambiente com seus possíveis acidentes ambientais, poluindo rios, o ar que respiramos, mares, subsolos, causando doenças nas sociedades, destruindo a fauna e flora de cada país etc. Para tentar amenizar os danos que as empresas vêm causando ao meio ambiente ao longo desses anos, muitas entidades têm adotado sistemas de gestão ambiental. 
As empresas estão tentando praticar o desenvolvimento sustentável, ou seja, utilizar os recursos naturais para produzir seus produtos sem prejudicar as gerações futuras de atenderem as suas necessidades, atingindo o equilíbrio do crescimento econômico com a proteção ambiental. Este conceito foi estabelecido pelo relatório da Brundtland Comission, em 1987, com o título de Our Common Future (Nosso Futuro em Comum). Esse documento propõe diversas ações e diretrizes a serem empreendidas para que se efetivem as mudanças necessárias, objetivando a redução das ameaças à sobrevivência e dar um rumo viável ao desenvolvimento.

Segundo Ribeiro (1998, p. 25), as empresas têm se preocupado em investir na modernização do seu parque industrial com novas tecnologias para preservação do meio ambiente:

\begin{abstract}
Constantes têm sido as notícias de que as empresas estão investindo cada vez mais em tecnologias de proteção e preservação do meio ambiente e, em alguns casos, até mesmo antecipando-se às exigências da legislação, o que tem contribuído para tornar os processos produtivos mais eficazes, proporcionando uma menor margem de refugos, fato que reduz o custo total dos insumos e o volume de emissões de resíduos líquido, gasoso ou sólido (RIBEIRO, 1998, p. 25).
\end{abstract}

De acordo com Cajazeira (1998, p. 3), existem diferentes razões para as empresas adotarem o sistema de gestão ambiental. As indústrias estão sob vários tipos de pressão como: financeiras, seguros, legislação, sociedades, governos, etc. A implantação de um sistema de gestão ambiental e a obtenção do certificado da norma ISO 14000 está se tornando uma exigência de fato, para as transações comerciais nacionais e internacionais.

Para as empresas assegurarem seu desenvolvimento, elas estão tendo que praticar o desenvolvimento sustentável e implantar um Sistema de Gestão Ambiental eficaz, alcançando assim, os objetivos estabelecidos. Recebendo a certificação da norma ISO 14000 e obedecendo as Leis relacionadas ao meio ambiente a entidade conseguirá se manter no mercado. Segundo Fernandes (2000, p. 4), um bom Sistema de Gestão Ambiental (SGA) pode ajudar a empresa a administrar a sua área de produção sem prejudicar o meio ambiente:

Um SGA eficaz pode auxiliar a empresa no gerenciamento, medição dos aspectos ambientais e suas operações, levando-a a uma conformidade mais eficiente com os requisitos ambientais obrigatórios e voluntários, podendo ainda auxiliar a empresa na adoção de novas posturas que produzam mudanças culturais e comportamentais, à medida que as práticas gerenciais ambientais forem sendo incorporadas nas operações gerais do negócio.

Segundo Costa (2000, p. 4), a preocupação com a preservação do meio ambiente já está atingindo algumas seguradoras, e estas estão exigindo das empresas seguradas, uma política de gestão ambiental. Portanto, pode-se dizer que, as empresas que possuem e estão implantando Sistema de Gestão Ambiental, estão tendo uma melhor chance de oportunidade para obter mais negócios nacionais e internacionais com investidores, acionistas, seguradoras, a sociedade, governos etc., aprimorando assim, o seu desenvolvimento.

\title{
4.1 Contabilidade Ambiental
}

A contabilidade é uma ciência social, pois ela acompanha o desenvolvimento do cenário econômico, político, cultural e social do patrimônio da entidade no qual ela está envolvida. (IUDÍCIBUS, 2000, p. 35). A contabilidade possui diferentes tipos de usuários. Iudícibus (2000, p. 19) considera como objetivo da contabilidade, o de: 
Fornecer aos usuários, independentemente de sua natureza, um conjunto básico de informações que, presumivelmente, deveria atender igualmente bem a todos os tipos de usuários, ou a contabilidade deveria ser capaz e responsável pela apresentação de cadastros de informações totalmente diferenciados, para cada tipo de usuário.

Com o surgimento das questões ambientais envolvendo as empresas, sociedades, governos etc, a contabilidade, como sistema de informação está se aprimorando de acordo com seus princípios, conceitos e métodos para desenvolver formas de registrar os eventos relacionados ao meio ambiente.

Kroetz (2000, p. 131) menciona e incentiva a criação de métodos de análise contábil, por meio da "criação de contas identificadas com responsabilidade social e ecológica da entidade, decorrente dos atos administrativos, portanto diferentes para cada entidade..."

De acordo com Kraemer (2002, p. 72), a contabilidade, como sistema de informação, deve informar todos os dados decorrentes da atividade da empresa, inclusive os dados que envolvem o meio ambiente, ajudando a administração na tomada de decisões. De acordo com Ribeiro (1992, p. 56), a contabilidade poderá estar inserida na causa ambiental. Assim,

a avaliação patrimonial, considerando os riscos e benefícios ambientais inerentes às peculiaridades de cada atividade econômica, bem como sua localização, poderá conscientizar os diversos segmentos de usuários das demonstrações contábeis sobre a conduta administrativa e operacional da empresa, no que tange ao empenho da empresa sobre a questão (RIBEIRO, 1992, p. 56).

Martins e De Luca (1994, p. 25), Tinoco (1994, p. 27), Bergamini Junior (2000, p. 311), e Antunes (2000, p. 06) corroboram com Ribeiro (1992, p. 56) no sentido de que a contabilidade ambiental pode ajudar aos gestores e outras partes interessadas com informações.

Assim, pode-se dizer que o objetivo da contabilidade ambiental é fornecer informações a todos os seus usuários, ou seja, os shareholers (acionistas) e stakeholders (investidores, clientes, empregados, fornecedores, sociedade, governos, diretores e demais interessados na organização), de forma que estes possam saber o que a empresa tem feito na área ambiental e qual decisão eles devem tomar com essas informações obtidas da contabilidade.

Ferreira (2003, p. 59) destaca que a contabilidade ambiental refere-se "a um conjunto de informações que relatem adequadamente, em termos econômicos, as ações de uma entidade que modifiquem seu patrimônio". E argumenta ainda que não se trata de uma nova contabilidade, mas de uma especialização dentro da contabilidade geral.

\subsection{Conceituação de Passivo Ambiental}

O passivo sempre foi visto como de fácil identificação. Segundo Iudícibus (2000, p. 139), "o problema principal do passivo não reside em sua avaliação, mas em quando reconhecê-lo e registrá-lo". Destaca-se o surgimento das questões ambientais, por exemplo, os acidentes ecológicos (Exxon-Valdez, no Alasca; pelos resíduos e materiais nucleares em Chernobil, na Rússia; pelo vazamento de 1,2 milhões de litros de óleo na Baia de Guanabara e acidentes com radioatividade em meados de setembro de 1987, com o caso do césio-137, em Goiânia), poluição atmosférica, desequilíbrio ecológico, uso descontrolado dos recursos naturais, contaminação dos lençóis freáticos, queimadas das florestas etc. Todos esses acontecimentos têm se tornado um risco do negócio que não tem sido evidenciado nas demonstrações contábeis, ou seja, o risco ambiental.

Destacam-se alguns conceitos conforme Freitas (2002, p. 115), Ribeiro (1998, p. 70) e Martins e De Luca (1994, p. 27) apresentados na literatura para o passivo ambiental, mas 
todas têm em comum o fato de serem gerados a partir do descumprimento de regulações ambientais que possam trazer prejuízo a outrem. Entende-se por contingências, as situações de riscos já existentes, envolvendo graus de incertezas variados quanto à sua real ocorrência e que, em função de eventos futuros, poderá resultar em ganhos ou perdas para a empresa. Os passivos contingentes podem ser entendidos como as obrigações originadas da possível ocorrência de uma transação ou evento futuro e, geralmente, estão relacionados a incerteza.

Segundo Ribeiro (1992, p. 105), "as contingências refletem os riscos a que a empresa está sujeita, visto a dependência de um evento futuro que poderá ocorrer ou não“. A importância do passivo ambiental das empresas destaca-se no momento de se tomar decisões, principalmente no caso de aquisição de alguma empresa.

Neste contexto, Sánchez (2001, p. 189) enfoca a crescente importância do passivo ambiental nas transações que envolvem a aquisição ou fusão de empresas.

\begin{abstract}
Além de regras contábeis e de exigências legais de reportar o passivo ambiental, o aumento de transações que envolvem a aquisição ou fusão de empresas, verificado internacionalmente nos últimos anos, as tem estimulado a quantificar seu passivo ambiental. Ao comprador interessa saber a totalidade dos passivos de uma empresa que está sendo adquirida - passivos financeiros, trabalhistas, ambientais -, pois seu valor deve ser descontado do preço da empresa. Quando a empresa à venda não dispõe de informações contábeis confiáveis, o comprador acaba exigindo uma auditoria, incluindo uma auditoria ambiental para avaliar o passivo. A contabilidade ambiental tem-se tornado, assim, uma exigência do próprio mercado (SÁNCHEZ, 2001, p. 189).
\end{abstract}

Pode-se começar a observar a importância de se entender o que é passivo ambiental e como ele pode ser um fator determinante para as empresas na tomadas de decisões. Portanto, pode-se verificar como o passivo ambiental das empresas tornou-se um fator determinante nas tomadas de decisões de interesse da própria entidade, como nas decisões que precisam ser tomadas pelos investidores, acionistas, governos, sociedade, empregados etc.

\title{
4.3 O Seguro Ambiental como Mecanismo de Minimização do Passivo Ambiental das Empresas
}

A busca de um desenvolvimento sustentável atribui importantes obrigações as empresas, aos governos e outras instituições. De acordo com Mello (1999, p. 20), estreita-se "a relação entre desenvolvimento, integração e meio ambiente, gerando-se a necessidade de estabelecer um ordenamento jurídico eficaz". Nesse contexto mundial, os passivos ambientais tornaram-se conhecidos devido aos desastres ecológicos ocorridos no mundo. Os danos ambientais causados por esses acidentes podem gerar sérias consequiências às empresas, segundo Ribeiro e Lisboa (2000, p. 15).

A partir dessa visão global, o seguro ambiental surge como instrumento, "juntamente com políticas públicas explícitas e compromissos empresariais firmes, constituem uma caixa de ferramentas que, se convenientemente utilizadas, podem prevenir a formação de passivos ambientais" (SÁNCHEZ, 2001, p. 193).

Bell e Pearlson (2003) argumentam que as pressões competitivas e as incertezas nos mercados financeiros têm feito com que os credores escolham cada vez mais uma variedade de produtos de seguros ambientais na tentativa de reduzir os potenciais passivos ambientais.

O grande problema na operacionalização desses seguros é devido ao fato de que os grandes poluidores não são enquadrados nos termos das leis ambientais existentes, Polido (2002, p. 07) diz que "praticamente inexistem indenizações substanciais que possam motivar outros a procurarem pelo seguro, como garantia de seus respectivos patrimônios". 
As contingências ambientais passivas "refletem os riscos a que a empresa está sujeita, visto a dependência de um evento futuro que poderá ocorrer ou não" (RIBEIRO, 1992, p. 103). Quando os riscos e incertezas ambientais, a que a empresa está sujeita, correlacionamse, os passivos ambientais tornam-se contingências passivas, que são originadas através do cumprimento de exigências legais; indenizações a terceiros por prejuízos causados e prevenção em relação a evento inesperado no caso das indústrias poluentes. Os passivos ambientais podem ser atenuados com a contratação de seguros ambientais.

Embora em muitas situações haja dificuldades em se detectar um risco ambiental, uma vez que em muitos casos estão ocultos, Gilbertson (2004) alerta que sobre a importância de se identificar os riscos ambientais associados às operações das empresas e assinala o seguro ambiental como o elemento central do programa de gestão de risco.

Porrini (2008) destaca que o tema seguro ambiental é complexo e exige atenção especial, principalmente quando são relacionadas as políticas de seguros e a cobertura dos riscos ambientais. Uma das tarefas mais difíceis é a determinação com grau de precisão a probabilidade de ocorrência e a magnitude dos danos ambientais, que muitas vezes tem formte relação com o sistema regulatório do País ou região envolvida (WARFEL, 2005).

Ao contratar o seguro ambiental, as empresas passam a ter um mecanismo imediato para disponibilidade de valores para resolver questões que vão, por exemplo, "recompor a empresa (se houve um acidente é porque existiu uma falha com danos materiais, provavelmente); ajudar a comunidade do entorno da empresa, dar uma satisfação a ela e ressarcir as perdas decorrentes do acidente" (POLUIÇÃO..., 2001, p. 20).

A minimização de passivos ambientais através dos seguros de riscos ambientais, já é uma realidade mundial. No Brasil, as empresas estão conscientizando-se de que controlar os seus riscos ambientais irá diminuir o seu passivo ambiental e, conseqüentemente, as seguradoras valorizarão as indústrias que buscam não agredir o meio ambiente com a implantação de sistemas de gestão ambiental eficaz e a prática do desenvolvimento sustentável.

\section{ORGANIZAÇÃO E ANÁLISE DOS DADOS}

São apresentados neste tópico os resultados obtidos a partir dos questionários respondidos pelas empresas seguradoras que operam no Brasil. Essa pesquisa tem como base, a resposta de onze seguradoras e duas resseguradoras, que equivalem a $18,31 \%$ dentre as 71 selecionadas. De acordo com as respostas dos questionários, constatou-se que a maior parte das seguradoras (85\%) não opera com Seguro de Riscos Ambientais.

$\mathrm{Na}$ questão dois, foram perguntados quais os tipos de coberturas oferecidas pelo seguro ambiental. Segundo as respostas, é a cobertura de poluição súbita/acidental, que faz parte do ramo de Responsabilidade Civil Geral (RCG), sendo chamada de cobertura básica e acessória; e a cobertura ampla, que abrange todas as coberturas especificadas pelo Seguro de Responsabilidade Civil - Poluição Ambiental, da Circular PRESI 023/97 (IRB, 1997).

$\mathrm{Na}$ terceira questão, foi questionado se o Seguro Ambiental é fácil de ser comercializado. Nesse caso, $100 \%$ das respondentes afirmaram que as empresas encontram dificuldades na venda deste tipo de seguro. De acordo com Walter Antonio Polido (2005) (diretor técnico da Munich Re), o seguro requer inspeções profundas antes da contratação, cujos custos devem ser suportados, em princípio, pelo proponente e não pela seguradora (informação verbal).

No Brasil, o seguro de Responsabilidade Civil Poluição Ambiental, por ser pouco operacionalizado, segundo Polido (1995, p. 135), os custos das inspeções prévias são suportadas, em geral, pelo Proponente do Seguro. A questão relacionada com os custos das inspeções e quem deve efetuar o pagamento das despesas é bastante dinâmica, pois poderá sofrer alterações de acordo a demanda do mercado para esse seguro. 
$\mathrm{Na}$ questão quatro foi abordado se existe demanda por parte das empresas seguradas para o seguro ambiental. Constatou-se que existem divergências no setor de seguros, quanto a essa questão, pois $50 \%$ das empresas consideram que não existe mercado e as outras $50 \%$ consideram que o mercado é promissor.

Devido ao reduzido número de resposta não se pode afirmar se existe demanda no mercado segurador brasileiro para os seguros ambientais. Polido (2005) ressalta que mercado para os seguros ambientais poderia ser maior se o judiciário nacional responsabilizasse com maior rigor aquelas empresas que causam danos ao meio ambiente (informação verbal).

Na quinta questão é levantada a importância da certificação da segurada na norma da série ISO 14000, para determinar o valor do prêmio do seguro. Constatou-se que $100 \%$ das seguradoras exigem que as seguradas estejam em conformidade com a ISO 14000, que é composto de prevenção, cuidado, segurança e preservação do meio ambiente.

Para Polido (2004) apenas aquelas empresas que investem em segurança e prevenção é que podem contratar o seguro específico de RC Poluição Ambiental, e que este seguro não constitui uma licença para poluir, pois não é essa a sua função primordial (informação verbal).

Na sexta questão, foi destacada a importância da norma ISO 14000 como fator de redução do prêmio de seguro. Constatou-se que 50\% das seguradoras reduzem o valor do prêmio de seguro para as empresas certificadas. E os outros $50 \%$ alegaram que não existe ainda, este grau de sofisticação quanto a tarifação dos riscos.

Foi perguntado também se as seguradoras acompanham o passivo ambiental das empresas, pois os passivos ambientais tornaram-se relevantes devido aos diversos acidentes ecológicos que ocorreram no Brasil e no Mundo. Das seguradoras entrevistadas, verificou-se que $50 \%$ não acompanham o passivo ambiental das empresas. E outras $50 \%$ acompanham o passivo ambiental das empresas por meio do Balanço Social e das Notas Explicativas das Demonstrações Contábeis.

Vale ressaltar que, embora 50\% disseram que acompanham, ainda é superficial, uma vez que há a percepção de que o número de informações sobre passivos ambientais, disponibilizadas pelas empresas em seus Balanços Sociais e Notas Explicativas, é bastante incipiente.

As questões oito e nove são direcionadas às empresas que não operam com Seguros Ambientais. Na oitava questão, foi abordado o interesse das seguradoras em operar com seguro ambiental. Observou-se que $73 \%$ das seguradoras, não pretendem operar com esse tipo de seguro, devido a diversas dificuldades (detalhadas na décima questão). Sendo que $9 \%$ não se pronunciaram sobre a questão e o restante (18\%) pretende operar com o seguro de riscos ambientais no futuro.

$\mathrm{Na}$ nona questão foi levantado o nível de conhecimentos das seguradoras sobre seguros ambientais. Constatou-se que $45 \%$ das seguradoras não possuíam conhecimento sobre o tema e que 55\% conheciam. De acordo com Polido (2002, p. 11), no mercado segurador brasileiro, no campo de seguros ambientais, existem questões a serem estudadas e discutidas, sendo “... um desafio, mas certamente poderá ser superado se houver, de fato, o interesse, bem como a vontade de um trabalho bem feito. É um mundo novo dentro do mundo de seguros a ser desbravado e conquistado".

Pode-se observar na Figura 2, que a participação das empresas estrangeiras é significativa, provocando o acirramento da concorrência, que é explicado por Souza (2001, p. 13) pela "abertura do mercado ao capital estrangeiro, a quebra do monopólio do IRB e a liberação das tarifas, por parte da SUSEP, no início dos anos 1990”. 


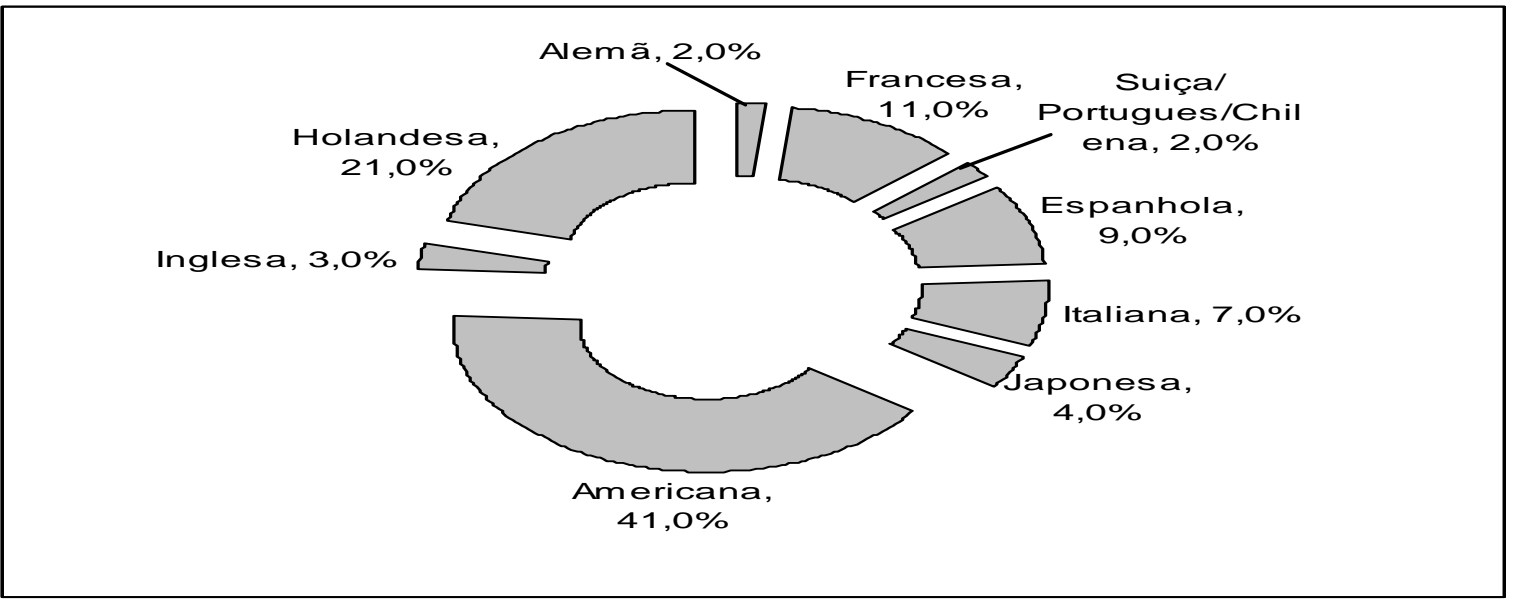

Figura 2 - Participação das empresas estrangeiras no mercado de seguros brasileiro Fonte: SUSEP (1999).

Loturco (2008) ressalta que após a quebra do monopólio do IRB houve a abertura do setor de resseguros, que movimenta o mercado de modo que gera expectativa para o mercado de trabalho na área de seguros. Inclusive Loturco (2008) ressalta que devido à falta de mãode-obra especializada as 20 resseguradoras estrangeiras sediadas no Brasil e outras vinte corretoras internacionais que devem aportar no país em 2009, buscam mão-de-obra de outros países na falta de mão-de-obra especializada.

Com relação às dificuldades em operar esse tipo de seguro, a falta de pesquisas acadêmicas que dêem suporte para as seguradoras operarem com seguro ambiental, representa 19\% (Figura 3), sendo esta, uma parcela significativa, pois foi a segunda maior dificuldade apontada pelas seguradoras.

Os itens sobre desconfiança entre seguradas e seguradoras, ocorridos devido a contratação de sinistros mal resolvidos anteriormente, foi considerado um obstáculo por apenas $4 \%$ das entrevistadas (Figura 3). Isso se deve à melhoria na elaboração dos contratos, nos quais, de acordo com o código civil "o segurado e o segurador são obrigados a guardar no contrato a mais estrita boa-fé em veracidade do objeto, circunstâncias e declarações a ele concernentes" (SOUZA, 2001, p. 31).

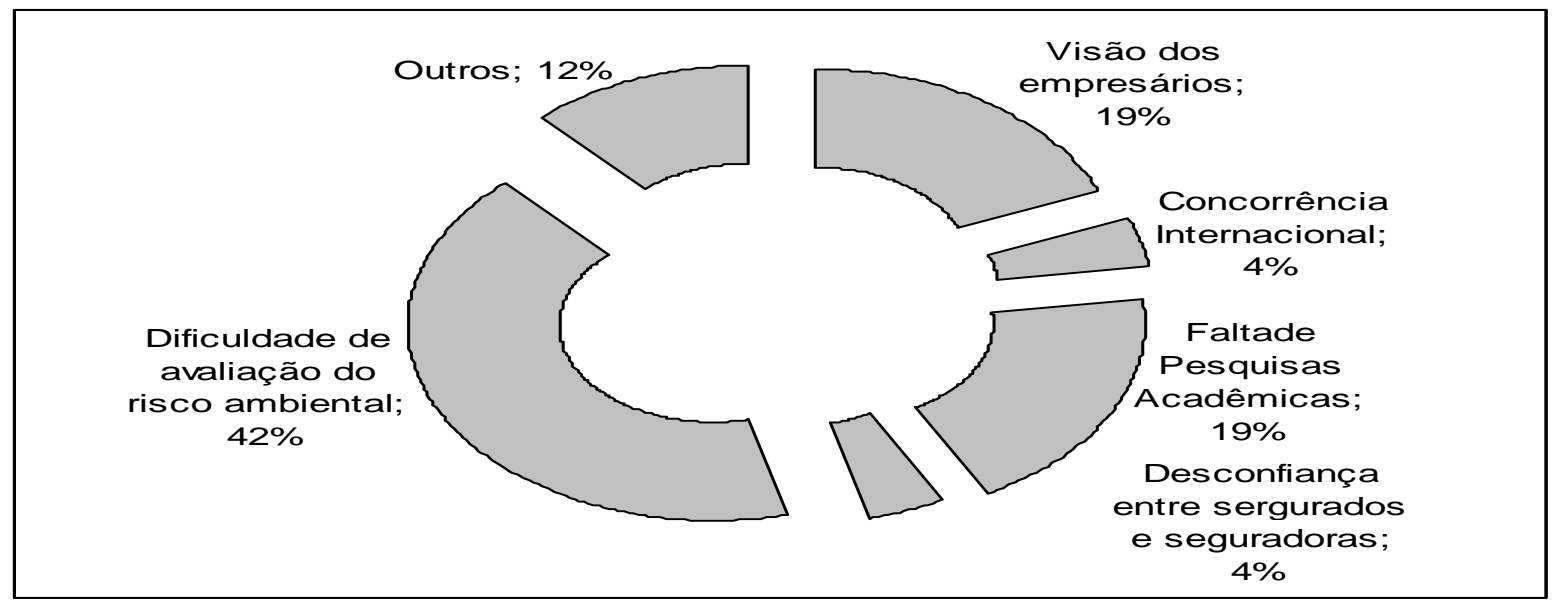

Figura 3 - As dificuldades para operar com seguros ambientais Fonte: dados da pesquisa.

A dificuldade na avaliação do risco ambiental representou 42\% (FIGURA 3), ou seja, foi considerado o maior obstáculo para as seguradoras operarem com segmento seguro de riscos ambientais. A dificuldade de se identificar os riscos, é um dos problemas fundamentais 
para execução do seguro ambiental, decorrendo a necessidade de conceituá-los e de haver concordância entre as partes envolvidas (HURTADO, 1997)

Nesta pesquisa, constatou-se que, $85 \%$ das empresas seguradoras, gostariam de receber um sumário da pesquisa com os principais resultados. Isso demonstra o interesse das empresas em conhecer mais sobre este ramo do seguro. De acordo com Polido (2002, p. 10), "o mercado nacional não poderá ficar apartado de tal evolução, caminhando de acordo o que se pratica em outros países".

\section{CONCLUSÃO}

Esta pesquisa procurou, além de expor como o seguro ambiental pode ser um mecanismo de minimização do passivo ambiental das empresas, saber suas características, verificar seu nível de oferta e demonstrar como esses seguros podem desempenhar um papel importante na gestão de recursos e conservação da natureza.

Para tanto, inicialmente, realizou-se uma revisão da literatura partindo-se dos aspectos gerais dos seguros, o surgimento dos seguros ambientais, regras gerais para a sua implantação, os sistemas de gestão ambiental e a utilização dos seguros ambientais como mecanismo de ajuda na diminuição de passivos ambientais.

Para coleta de dados, o principal instrumento foi o questionário (enviado a 71 seguradoras filiadas à FENASEG, das quais, 13 retornaram resposta), através do qual, procurava-se verificar o funcionamento dos seguros ambientais e sua oferta no Brasil. Todas as análises tomam como base essa amostra.

Diante dos dados obtidos com a pesquisa empírico-analítica, os resultados foram descritos de conformidade com as informações constantes dos questionários, para finalmente, analisá-los à luz dos conhecimentos sobre contabilidade e seguros ambientais.

Os seguros de riscos ambientais são caracterizados por várias coberturas de Responsabilidade Civil. De acordo com a atividade do proponente, o risco pode ser alocado em vários tipos de ramos de seguro ambiental. Entre eles, destacam-se: o ramo de Responsabilidade Civil Geral, no qual, faz parte o Seguro de Responsabilidade de Estabelecimentos Comerciais ou Industriais que oferece a cobertura básica e súbita/acidental, também denominada de acessória, e a Circular PRESI 023/97 (IRB, 1997), que institui o Seguro de Responsabilidade Civil Poluição Ambiental no qual oferece a cobertura ampla, que atende a poluição súbita e gradual. Esta apólice de seguro também garante a Responsabilidade Civil do Segurado em relação às reparações por danos corporais ou materiais e as despesas judiciais na esfera civil e criminal.

Observou-se neste estudo que o nível de oferta do seguro de riscos ambientais no Brasil como mecanismo de ajuda na minimização de passivos ambientais, ainda é pequena devido às diversas dificuldades que o mercado segurador enfrenta para operar com este tipo de seguro. Dessa forma, conclui-se com esta pesquisa, que existe a necessidade de se ampliar o conhecimento do mercado segurador brasileiro em relação à subscrição de riscos ambientais e coberturas mais complexas, que apresentem soluções adequadas ao empresariado, que começa a questionar a sua exposição a esse tipo de risco.

Das treze seguradoras entrevistadas, apenas quatro operam com seguros de riscos ambientais, esse número indica a situação do mercado segurador brasileiro, frente à operação do seguro e riscos ambientais. Somente com políticas públicas estruturadas, um empresariado compromissado com a preservação do meio ambiente e um mercado segurador preparado, o seguro ambiental tornará, além de um instrumento de preservação ambiental, um mecanismo de ajuda na diminuição dos passivos ambientais das empresas seguradas. Uma das limitações da pesquisa é o número de respondentes, considerando principalmente que o mercado de seguro ambiental é ainda incipiente e poucas seguradoras o tem comercializado devido principalmente ao seu alto nível de complexidade na contratação. Espera-se que o presente 
estudo sirva como incentivo para que outras pesquisas se voltem para as questões aqui propostas.

\section{REFERÊNCIAS}

ANTUNES, Cleber do Carmo. Sociedades sustentáveis: a responsabilidade da contabilidade. In: CONGRESSO BRASILEIRO DE CONTABILIDADE, 16., 2000, Goiânia. Anais ... Brasília: CFC, 2000. 1CD-ROM.

BELL, Michael J.; PEARLSON, Jonathan. Environmental insurance: a financing facilitator. Briefings in Real Estate Finance. v. 3, n. 3, p. 236-241, jan. 2004. http://dx.doi.org/10.1002/bref.104

BERGAMINI JUNIOR, Sebastião. Avaliação contábil do risco ambiental. Revista do BNDS. v. 7, n. 14, p. 301-328, dez. 2000.

BRASIL 500 anos. Uma breve história do seguro. Disponível em: <http://www.agzseguros.com.br/historia.htm>. Acesso em: 25 ago. 2002.

BRASIL. Constituição (1988). Constituição [da] República Federativa do Brasil. São Paulo: Rideel, 2000.

BRASIL. Lei $n^{\circ}$ 6.938, de 31 de agosto de 1981. Dispõe sobre a Política Nacional do Meio Ambiente, seus fins e mecanismo de formulação e aplicação, e dá outras providências. Diário Oficial [da] República Federativa do Brasil, Brasília, 2 set. 1981. Disponível em: <http://www2.ibama.gov.br/duvidas/lei_6938.htm>. Acesso em: 04 set. 2002.

BRASIL. Lei $\mathrm{n}^{\circ}$ 9.605, de 12 de fevereiro de 1998. Dispõe sobre as sanções penais e administrativas derivadas de condutas e atividades lesivas ao meio ambiente, e dá outras providências. Diário Oficial [da] República Federativa do Brasil, Brasília, 13 fev. 1998. Disponível em: 〈http://www2.ibama.gov.br/duvidas/lei_9605.htm〉. Acesso em: 04 set. 2002.

CAJAZEIRA, Jorge Emanuel Reis. ISO 14001: manual de implantação. Rio de Janeiro: Qualitymark, 1998.

COSTA, Norma Beatriz Camacho. A Contabilidade como instrumento para melhoria das políticas ambientais. In: CONGRESSO BRASILEIRO DE CONTABILIDADE, 16., 2000, Goiânia. Anais ... Brasília: CFC, 2000. 1CD-ROM.

DURÇO, Roberto. Desastres ecológicos: seguro ambiental. Revista APMP, p. 49-53, dez./fev. 2001.

FERNANDES, José Wilson Nunes. A gestão ambiental e o desenvolvimento sustentável sob a ótica da contabilidade ambiental. In: CONGRESSO BRASILEIRO DE CONTABILIDADE, 16., 2000, Goiânia. Anais ... Brasília: CFC, 2000. 1CD-ROM.

FERREIRA, Aracéli Cristina de Souza. Contabilidade ambiental: uma informação para o desenvolvimento sustentável. São Paulo, Atlas, 2003.

FREITAS, Vladimir Passos de. Direito ambiental em evolução. Curitiba: Juruá, 2002.

GILBERTSON, Peter A. Environmental insurance: crucial coverage in a volatile climate. National Underwriter / Property \& Casuality Risk \& Benefits Management. v. 108, n. 14, p. 16-19, dez. 2004. GLOSSÁRIO. Definições de termos usualmente empregados pelo mercado segurador. Fenaseg on-Line. Disponível em: <http://www.fenaseg. org.br/glossario.htm>. Acesso em: 06 ago. 2002. 
GOMES, Célia; PEREIRA, Eduardo. Seguro de responsabilidade civil poluição ambiental. Disponível em: <http: //www.diramb.gov.pt/data/basedoc/txt_d_9166_1_0001.html>. Acesso em: 24 set. 2002.

GREEN, Paula L. Insurance cleans up the balance sheet. Global Finance, v. 16, n. 6, p. 27 28, jun. 2002.

HISTÓRIA do seguro no Brasil. Disponível em: <http://www.bradescoseguros.com.br/historia/rightframe_historia_seguro_evolucao.html>. Acesso em: 25 ago. 2002.

HISTÓRIA do seguro. Disponível em: <http://www.npvseguros.com.br/historia/historia.htm>. Acesso em: 25 ago. 2002a.

HISTÓRIA do seguro: início da atividade seguradora no Brasil. Anuário Estatístico da SUSEP. Disponível em: <http://www.susep.gov.br/menususep/historiadoseguro.htm>. Acesso em: 25 ago. 2002b.

HURTADO, Natalie Haanwinckel. Seguro de riscos ambientais. Centro de Estudos e Pesquisas em Seguros, texto para discussão $n^{\circ}$ 2. COPPEAD-UFRJ, Rio de Janeiro, 1997. Disponível em: <http://www.coppead.ufrj.br/ceps.htm>. Acesso em: 19 jul. 2002.

INSTITUTO DE RESSEGUROS DO BRASIL (IRB). Circular PRESI-023, de 1\%\%8/ 1997 - RCGER-001/97 - Ramo Responsabilidade Civil Geral. Seguro de Responsabilidade Civil Poluição Ambiental e revoga a Circular PRESI-052 de 26 dez. 1991. Rio de Janeiro, 1997.

IUDICIBUS, Sérgio de. Teoria da contabilidade. 6. ed. São Paulo: Atlas, 2000.

KRAEMER, Maria Elisabeth Pereira. Contabilidade ambiental como sistema de informações. Revista Brasileira de Contabilidade, n. 133, p. 69-83, jan./fev. 2002.

KROETZ, César Eduardo Stevens. Balanço social: teoria e prática. São Paulo: Atlas, 2000.

LEAL, Luciana Nunes. Diretor do Pnuma reconhece falta de ações concretas. Estadão. São Paulo, 22 jun. 2002. Disponível em: <http://www.estadao.com.br/ciencia/noticias/2002/jun/22/134.htm>. Acesso em: 04 set. 2002.

LOTURCO, Roseli. Adeus monopólio: abertura do setor de resseguros movimenta o mercado e a expectativa é de que 1000 vagas sejam criadas. Revista Você S/A, Ed. 122, p. 34-35, ago. 2008.

MACDOWELL, Silvia Ferreira; CORRÊA, Silvia Fernanda Meio ambiente e o mercado financeiro. In: ENCONTRO NACIONAL SOBRE GESTÃO EMPRESARIAL E MEIO AMBIENTE, 4, São Paulo. Anais ... São Paulo, 1997. pp. 287-305.

MARTINS, Eliseu; DE LUCA, Márcia M. Ecologia via contabilidade. Revista Brasileira de Contabilidade, ano 23, n. 86, p. 20-29, mar. 1994.

MARTINS, Eliseu. Contabilidade de custos. 7. ed. São Paulo: Atlas, 2000.

MARTINS, Gilberto de Andrade. Manual para elaboração de monografias e dissertações. 2. ed. São Paulo: Atlas, 1994.

MELLO, Sérgio Barroso de. Um novo e crescente risco. Revista Cadernos de Seguro, Rio de Janeiro, p. 20-26, nov./dez. 1999.

MENDONÇA, Ângela; SOUZA, Marco Aurélio G. de. Os 5 P's: seguro de RC poluição ambiental: uma proposta de critério para aceitação. Revista Cadernos de Seguro. Rio de Janeiro, p. 21-24, maio 2002. 
MINC, Carlos. A linguagem da prevenção. Revista Cadernos de Seguro. Rio de Janeiro, p. 13-18, maio 2002.

POLIDO, Walter Antonio. Uma introdução ao seguro de responsabilidade civil - poluição ambiental. São Paulo: Manuais Técnicos de Seguros, 1995.

POLIDO, Walter Antonio. Além de uma nova 'onda'. Revista Cadernos de Seguro. n. 112, p. 6-11, maio 2002.

POLIDO, Walter Antonio. Seguro de responsabilidade civil - poluição ambiental. Pool brasileiro de riscos ambientais - PBRA: uma solução para o problema de subscrição? Disponível em: http://www.jurinforma.com.br/notas/0061.html > Acesso em: 12 ago. 2002a.

POLIDO, Walter Antonio. Seguro para riscos ambientais. Revista Brasileira Risco e Seguro. v.1, n.0, p. 136-143, dez. 2004.

POLIDO, Walter Antonio. Seguro para riscos ambientais. São Pauto: RT, 2005. Poluição ambiental: risco para todos, cobertura para poucos. Revista Apólice, São Paulo, n. 43, p. 1620, abr. 2001.

PORRINI, Donatella. Law and economics of environmental insurance. Genova Papers on

Risk \& Insurance - Issues \& Practice. v. 33, n. 2, p. 269-273, abr. 2008. doi:10.1057/gpp.2008.11

RIBEIRO. Maísa Souza. Contabilidade e meio ambiente. 1992. Dissertação (Mestrado em Controladoria e Contabilidade) - Faculdade de Economia, Administração e Contabilidade, Universidade de São Paulo (USP), São Paulo, Brasil, 1992.

RIBEIRO. Maísa Souza. Custeio das atividades de natureza ambiental. 1998. Tese (Doutorado em Controladoria e Contabilidade) - Faculdade de Economia, Administração e Contabilidade, Universidade de São Paulo (USP), São Paulo, Brasil, 1998.

RIBEIRO, Maísa Souza; LISBOA, Lázaro P. Passivo ambiental. Revista Brasileira de Contabilidade, Brasilia-DF, ano 29, n. 126, p. 8-19, 2000.

SÁNCHEZ, Enrique Luis. Desengenharia. São Paulo: Edusp, 2001.

SOUZA, Sidney de. Seguros: contabilidade, atuária e auditoria. São Paulo: Saraiva, 2001.

TINOCO, João Eduardo Prudêncio. Ecologia, meio ambiente e contabilidade. Revista Brasileira de Contabilidade, Brasília, ano 23, n. 89, p. 24-31, nov. 1994.

WARFEL, William J. Environmental insurance coverage disputes: is State legislation the solution? CPCU eJournal. v. 58, n. 9, Set. 2005. p. 1-12. 